\title{
Proliferative Heterogeneity in the Human Prostate: Evidence for Epithelial Stem Cells
}

\author{
David L. Hudson, Michael O'Hare, Fiona M. Watt, and John R.W. Masters \\ Institute of Urology and Nephrology (DLH, JRWM), Research Laboratories, and LICR/UCL Breast Cancer \\ Laboratory (MO), Department of Surgery, University College London Medical School, University of London, and \\ Keratinocyte Laboratory (FMW), Imperial Cancer Research Fund, London, United Kingdom
}

SUMMARY: Clonal analysis of human prostate epithelial cells was undertaken in order to identify stem cells. Two types of colony were distinguished, termed type I and type II. Type I colonies were relatively small and irregular and contained a loose mixture of differentiated and undifferentiated cells. In contrast, type II colonies were large, round, and homogeneous, consisting almost exclusively of small undifferentiated and dividing cells. The colony-forming efficiency was $5.8 \% \pm 1.8$ for freshly isolated epithelial cells. There were approximately 10 times as many type I as type II colonies and about 1 in 200 of the plated cells was capable of forming a type II colony. In three-dimensional culture on Matrigel, the type II colonies produced structures reminiscent of prostate epithelium, with luminal cells expressing markers of prostate epithelial differentiation, including the androgen receptor. On the basis of their proliferative characteristics and pluripotency, the type II colonies may be the progeny of stem cells and the type I colonies of a more differentiated transit-amplifying population. (Lab Invest 2000, 80:1243-1250).

$$
T
$$
he prostate is the site of two of the most frequent medical problems in elderly men, benign prostatic hyperplasia $(\mathrm{BPH})$ and prostate cancer. During middle age the transition zone of the prostate begins to enlarge as a result of BPH, causing bladder outflow obstruction. $\mathrm{BPH}$ is the second most common reason for surgery in men above the age of 65 years (Oesterling, 1995). Prostate cancer is the most frequently diagnosed cancer in men in the United States, with a projected incidence for 1999 of 179,000 new cases and 37,000 deaths (Landis et al, 1999). Epithelial stem cells are involved in the etiology of both $\mathrm{BPH}$ and prostate cancer (Bonkhoff and Remberger, 1996; Isaacs and Coffey, 1989). However, there are no markers for prostate epithelial stem cells, and these cells have not been isolated or characterized.

Although there is little information regarding epithelial stem cells in the prostate, more is known about stem cell characteristics in other mammalian epithelial tissues, such as the lining of the gut (Potten and Loeffler, 1990) and skin epidermis (Jones and Watt, 1993; Jones et al, 1995; Li et al, 1998). In both of these tissues, there is evidence of a small population of stem cells whose progeny are either stem cells or cells with more limited proliferative capacity, termed transitamplifying cells. Although the latter can be rapidly dividing, their progeny are ultimately destined to differentiate and will be lost from the proliferative com-

Received March 10, 2000.

DLH is supported by National Institutes of Health Grant AG14960-02. Address reprint requests to: Dr. David L. Hudson, Institute of Urology and Nephrology, Research Laboratories, University College London Medical School, University of London, 67-73 Riding House Street, London W1P 7PN, UK. Fax:0044 (0) 207679 9366; E-mail:d.hudson@ucl.ac.uk partment. In some epithelial tissues, such as the gut (Potten and Loeffler, 1990), the stem cells may be pluripotent, producing different cell lineages, while other tissues, such as the epidermis, have a single cell lineage (Watt, 1989).

Human prostate epithelium consists of two layers, basal and luminal. Cells in the luminal layer express prostate specific antigen (PSA), prostatic acid phosphatase, androgen receptor, and keratins $(\mathrm{K}) 8$ and 18. In contrast, cells of the basal layer express $\mathrm{K} 5$ and $\mathrm{K} 14$, but not PSA, prostatic acid phosphatase, or androgen receptor (Xue et al, 1998). More than $80 \%$ of the proliferative cells are seen in the basal layer, and because there are approximately 3 times as many luminal as basal cells, the proliferative index is about 10-fold higher in the basal layer (Bonkhoff et al, 1994; Hudson et al, unpublished observations). Consequently the basal layer is thought to contain epithelial stem cells (Bonkhoff et al, 1994; Bonkhoff and Remberger, 1996) that give rise to an intermediate amplifying population, the progeny of which differentiate into the secretory luminal cells (Xue et al, 1998).

Keratinocyte stem cells were isolated from human epidermis using cell surface expression of $\beta 1$ integrins and rapid adhesion to extracellular matrix (Jones and Watt, 1993; Jones et al, 1995). The cells with the highest colony-forming efficiency adhered most rapidly to collagen. Attempts to find markers for the purification of prostate epithelial stem cells have so far been unsuccessful, although it is assumed that they are amongst the $\mathrm{K} 5 / 14$ positive cells in the basal layer (Xue et al, 1997). One candidate cell surface marker that is overexpressed by prostate cancer cells and is detected on a subset of epithelial cells has been termed "prostate stem cell antigen" because of its 
homology with stem cell antigen 2 (Reiter et al, 1998). There is also evidence for a p2 $7^{\mathrm{kip} 1}$ negative population in the basal cell compartment, which may represent the transit-amplifying cells (De Marzo et al, 1998).

Prostate epithelial cells have been cloned directly from biopsies and from primary cultures (Peehl and Stamey, 1986, 1988), but there have been no studies analyzing the properties of these cells. The aim of our study was to undertake a clonal analysis of proliferative heterogeneity in freshly isolated prostate epithelial cells. Primary cultures were grown at clonal density, and two types of colony were identified, which, on the basis of their proliferative characteristics and pluripotency, are the progeny of stem cells and a more differentiated transit-amplifying cell population.

\section{Results and Discussion}

\section{Clonogenicity and Proliferative Heterogeneity in Primary Epithelial Cell Cultures}

Epithelial cells were cloned directly from biopsies of benign prostatic hyperplasia. There was considerable variation in the colony-forming ability, which ranged from $0.9 \%$ to $12.3 \%$, with a mean of $5.8 \pm 1.8 \%$ (Table 1). The clonogenicity of freshly isolated human prostate epithelial cells was almost identical to that described by Peehl et al (1988), despite the use of a different serum-free culture medium. However, since only approximately $25 \%$ of the epithelial cells are derived from the basal layer where most of the proliferative cells are found (Bonkhoff et al, 1994), this may represent a colony-forming efficiency of potentially proliferative basal cells approximately 4 times greater. This is close to the figure of $25 \%$ described by Peehl et al (1988) when they measured the colony-forming efficiency of primary cultures of prostate epithelial cells.

Table 1. Colony-Forming Efficiencies of Primary Cultures of Prostate Epithelial Cells ${ }^{a}$

\begin{tabular}{cccc}
\hline $\begin{array}{c}\text { Experiment } \\
\text { No. }\end{array}$ & $\begin{array}{c}\text { Mean total } \\
\text { CFE } \geq 32 \\
\text { cells }\end{array}$ & $\begin{array}{c}\text { \% CFE } \\
\text { type II } \\
\text { colonies }\end{array}$ & $\begin{array}{c}\text { \% total } \\
\text { colonies } \\
\text { type II }\end{array}$ \\
\hline 1 & 12.3 & 1.23 & 10.0 \\
2 & 2.1 & 0.00 & 0.0 \\
3 & 4.8 & 0.47 & 9.8 \\
4 & 8.4 & 1.35 & 16.6 \\
5 & 4.4 & 0.27 & 6.0 \\
6 & 0.9 & 0.27 & 30.8 \\
7 & 18.0 & 1.03 & 5.7 \\
8 & 2.3 & 0.37 & 15.7 \\
9 & 1.3 & 0.00 & 0.0 \\
10 & 3.7 & 0.40 & 10.7 \\
Mean & 5.8 & 0.54 & 10.5 \\
SEM & 1.8 & 0.16 & 2.87 \\
\hline
\end{tabular}

${ }^{a}$ Cells $\left(10^{3}\right)$ were plated into dishes coated with type I collagen and seeded with lethally irradiated 3T3 cells. The cultures were allowed to grow for 14 days before being fixed with formaldehyde and stained with $1 \%$ Rhodanile stain. Colonies with 32 cells or more were counted and the mean determined from 3 replicate dishes per experiment. Colonies were either scored as type I or II (Fig. 1).

CFE, colony-forming efficiency.
Two types of colony were distinguishable after 14 days of growth (Fig. 1). Type I colonies were relatively small, up to a maximum of $4 \mathrm{~mm}$ across, and had fewer than 30 cells per linear millimeter (Fig. 1A). Type II colonies were $3 \mathrm{~mm}$ or greater in diameter and consisted mainly of small cells at a high density of between 30 and 50 cells per millimeter (Fig. 1C). The type II colonies were generally round in outline, whereas the type I colonies tended to be irregular.

The dishes from the 10 separate samples were scored for the number of type I and type II colonies (Table 1). Type II colonies developed in 8 cultures and accounted for between $5.7 \%$ and $30.8 \%$ of the total colony count. The mean proportion of type II colonies was $10.5 \%$ of the total, giving an approximate frequency of 1 in 200 plated cells.

\section{Proliferative Heterogeneity}

The number of cells in every colony containing more than 32 cells was scored in three experiments (Fig. 2). The distribution corresponded to the two types of colony. Type I colonies contained up to 8,500 cells, and type II colonies contained between 8000 and 40,000 cells. Assuming $100 \%$ proliferative capacity within the colonies, the type II colonies undergo 12 to 14 population doublings, whereas type I colonies are only capable of 5 to 12 population doublings in 14 days. In one experiment, one type II colony had grown to approximately 40,000 cells, representing 15 cell doublings or more than one doubling every 24 hours. Although occasional colonies had characteristics which overlapped those of the other colony type, even the largest type I colonies were irregular and contained areas with loosely associated large cells.

\section{Immunocytochemistry}

Colonies were co-stained for keratin $\mathrm{K} 14$, a marker for basal cells, and K8, a marker for luminal cells (Fig. 3). The smallest colonies, those with approximately 32 cells (Fig. 3A), contained only K8 positive cells. The larger type I colonies (Fig. 3B) contained some cells expressing only $\mathrm{K} 14$ or $\mathrm{K} 8$, but many of the cells expressed both keratins. The large type II colonies (Fig. 3C) were composed mainly of K14 positive cells with little or no expression of K8. It seemed that there was an inverse relationship between proliferation and differentiation in these colonies.

\section{Differential Adhesion}

To study differential adhesion, freshly isolated epithelial cells were allowed to attach to collagen I-coated dishes for 5 or 20 minutes, and unattached cells were removed by washing. Between $38 \%$ and $59 \%$ of the clonogenic cells (mean, $45 \%$ ) attached within 5 minutes of plating, and after 20 minutes $56 \%$ to $80 \%$ of clonogenic cells had adhered (Table 2). Studies of epidermal stem cells have shown that the proliferative cells can be selected by their expression of higher levels of cell surface $\beta 1$ integrins (Jones and Watt, 1993) or $\alpha 6$ integrin ( $\mathrm{Li}$ et al, 1998) and their rapid 

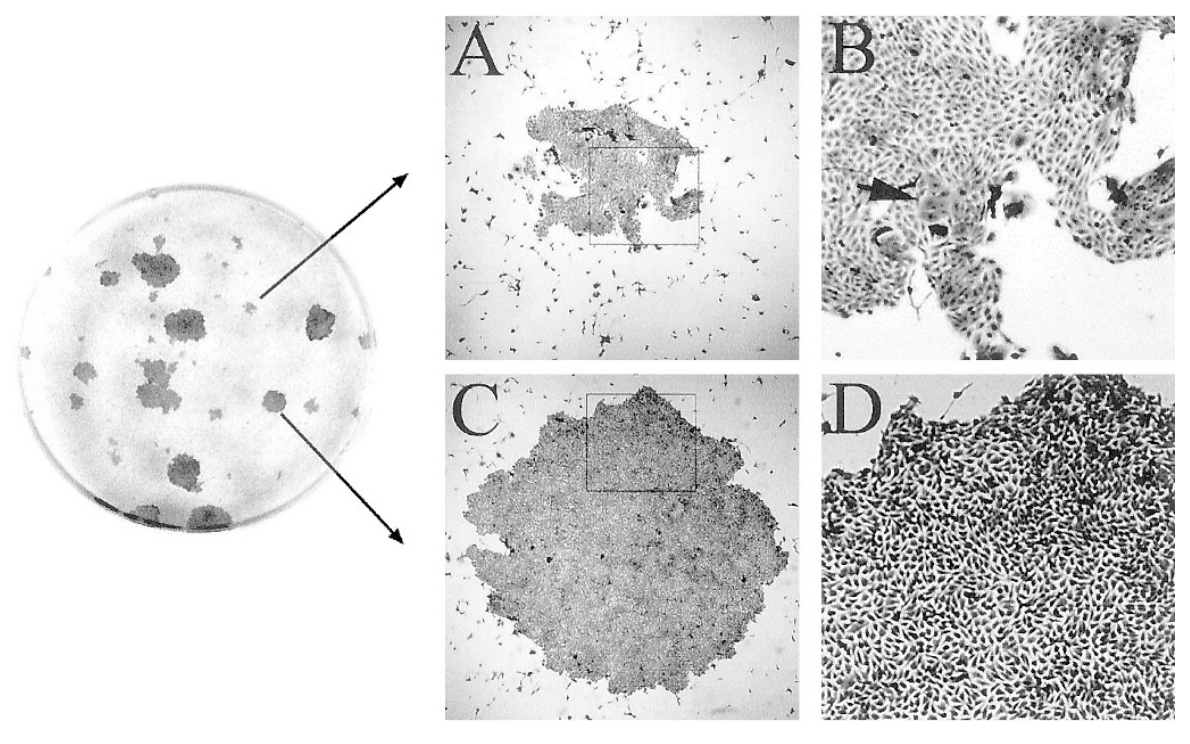

\section{Figure 1.}

Colony types formed in primary cultures of prostate epithelial cells. Freshly isolated epithelial cells $\left(10^{3}\right)$ were plated onto a 6 -cm dish with a feeder layer of irradiated $3 T 3$ cells and grown for 14 days. The cells were fixed and stained. Two types of colony were formed: Type 1 (A) are relatively small with a mixture of small proliferative and larger differentiated cells. These colonies are irregular in shape, have a cell density below 30 cells per linear millimeter, and contain from 32 to 8500 cells. Type II colonies (C) are large (at least $3 \mathrm{~mm}$ in diameter) and regular in shape. They consist mainly of small cells and have a high density of between 30 and 50 cells per millimeter. Type II colonies contain between 8000 and 40,000 cells after 14 days of culture.

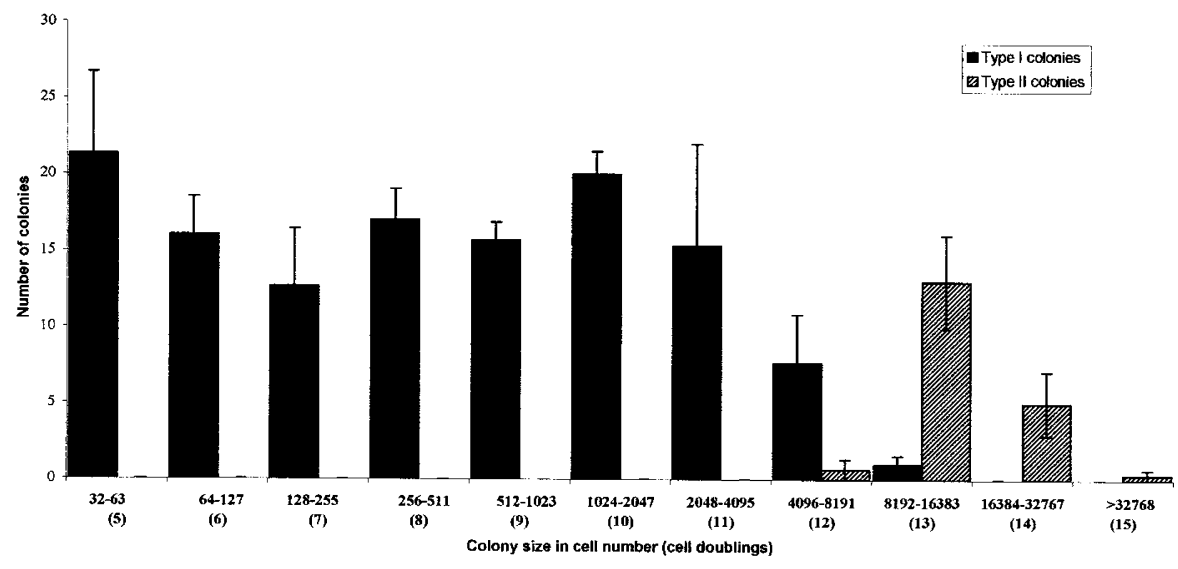

\section{Figure 2.}

Distribution of colony size and type in primary cultures of epithelial cells. Epithelial cells $\left(10^{3}\right)$ were plated in 6 -cm dishes, allowed to grow for 14 days, and then fixed and stained. Each colony larger than 32 cells was scored for cell number and colony type. Every colony in three dishes from three separate samples was counted (approximately 150 colonies per sample). The data shown is the mean of three experiments, and error bars show the standard error of the mean (SEM).

attachment to extracellular matrix. While proliferative prostate epithelial cells were also selected by their rapid attachment to collagen I, this did not preferentially select for the type II colony-forming cells (Figure 4).

From eight experiments in which cells were allowed to attach and then were harvested and counted, a mean of $8.8 \pm 2.8 \%$ of plated cells attached within 5 minutes. Thus, the most rapidly attaching $8.8 \%$ of cells contained $45 \%$ of colony-forming cells, a 5 -fold enrichment over the total number of cells plated.

\section{Pluripotency}

One characteristic of stem cells from some tissues is pluripotency, or the capacity to regenerate a complete repertoire of tissue-specific cell types. To determine whether the type II colonies were capable of regenerating prostate epithelium, individual colonies were harvested and plated onto Matrigel. After 3 days the cells formed clumps that developed into threedimensional spherical structures (Fig. 5A), with sidebranching after 7 to 17 days. Occasionally these structures appeared to be connected by ducts (Fig. 5B). Nuclear staining with Hoechst 33258 showed that the ducts consisted of a monolayer of cells surrounding a tube (Fig. 5C).

Stained sections of the spherical structures showed a well-organized basal layer and one or more luminal layers of larger, more flattened cells surrounding a lumen partly filled by single cells (Fig. 5, D to I). Antibodies to both K5 (Fig. 5D) and K14 (Fig. 5, E and 

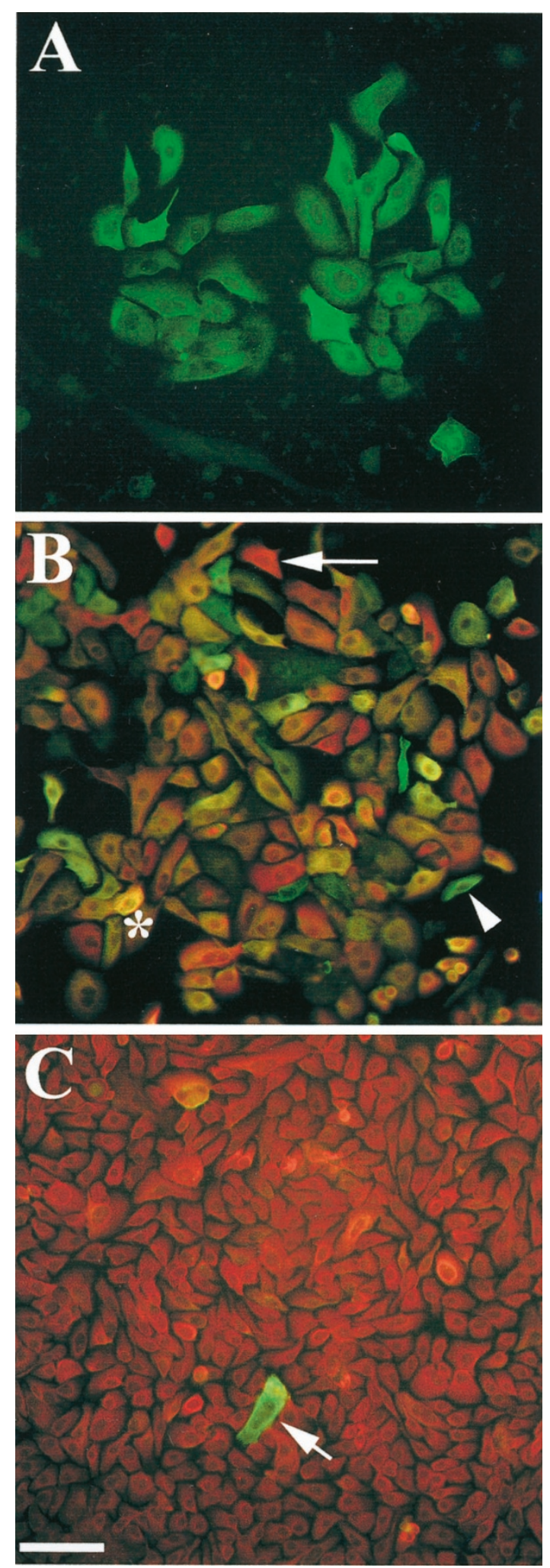

Figure 3.

Immunofluorescence analysis of keratin expression. Freshly isolated epithelial cells were plated at $10^{3}$ cells per $6-\mathrm{cm}$ dish and grown for 14 days. Dishes were fixed and stained simultaneously with monoclonal antibodies against keratins 8 and 14. Ig isotype-specific fluorescently conjugated secondary antibodies were used to detect anti-K8 in green and anti-K14 in red. B, Cells expressing K8 alone (green, arrowhead), K14 alone (red, arrow), or both simultaneously (yellow, asterisk) are indicated. C, The arrow indicates a single K8 positive cell in this field. Bar represents $100 \mu \mathrm{m}$. Original magnification: $\times 200$.
F) stained most of the cells, although the cells in the luminal layers stained more weakly. Double staining for $\mathrm{K} 14$, together with either anti-K17 (Fig. 5E) or K19 (Fig. 5F), showed that the luminal layers preferentially expressed both these markers and K8 (Fig. 5G). Androgen receptor was expressed by cells that had sloughed into the lumen. To confirm its specificity, androgen receptor staining was compared with that of an IgG isotype-matched anti-CD44 antibody. This stained the outer basal cells only, with no reactivity seen in the upper layers or lumen (Fig. $5 \mathrm{l}$ ). This pattern of CD44 staining corresponds to that seen in vivo, in which only the basal layer is positive (Liu et al, 1997). However, no staining was seen in the androgenpositive cells for PSA or prostatic acid phosphatase (data not shown), which may represent the final step in the terminal differentiation of prostate epithelial cells. In previous studies, primary cultures of prostate epithelial cells produced PSA only in the presence of stromal cells (Bayne et al, 1998; Liu et al, 1997)

It is unlikely that colonies produced by stem cells are composed solely of stem cells, because they would be expected to contain a mixture of stem cells and transit-amplifying cells (Barrandon and Green, 1987). Our studies of the growth of cells from type II colonies in three-dimensional cultures support this idea because a structure with both a basal and a differentiated population is produced. The findings also confirm evidence that basal cells produce a differentiated progeny that includes the luminal population (Liu et al, 1997; Robinson et al, 1998). The three-dimensional structures in Matrigel may prove to be a useful model for studying differentiation pathways in normal prostate cells.

We have yet to identify a marker for prostate epithelial stem cells in situ. Further characterization of the keratinocyte stem cell population has shown that, in addition to the high levels of cell surface integrins and $\gamma$-catenin, these cells also have low levels of E-cadherin and $\beta$-catenin (Akiyama et al, 2000; Molès and Watt, 1997) in tissue and high levels of noncadherin-associated $\beta$-catenin in culture (Zhu and Watt, 1999). Li et al (1998) have also shown that a subset of the integrin bright keratinocytes with stem cell characteristics have low expression of the proliferation marker recognised by antibody 10G7. Further study of molecules such as these is required to determine whether their distribution is consistent with that of prostatic stem cells. It is anticipated that the type II colonies will provide a resource with which to identify and characterize individual prostate epithelial stem cells.

\section{Materials and Methods}

\section{Tissue Acquisition}

Human prostate tissue was obtained from patients between the ages of 51 and 86 years who were undergoing transurethral resection of the prostate for $\mathrm{BPH}$. The tissue was transferred to RPMI1640 medium (Life Technologies, Paisley, United Kingdom) 
Table 2. Timecourse of Epithelial Attachment to Extracellular Matrix ${ }^{a}$

\begin{tabular}{|c|c|c|c|c|c|c|}
\hline $\begin{array}{c}\text { Experiment } \\
\text { No. }\end{array}$ & $\begin{array}{l}\text { Adhesion } \\
\text { time }\end{array}$ & $\begin{array}{l}\text { Type I } \\
\text { CFE }\end{array}$ & $\begin{array}{c}\text { Type II } \\
\text { CFE }\end{array}$ & $\begin{array}{l}\text { Total } \\
\text { CFE }\end{array}$ & $\begin{array}{c}\text { Type II CFE as } \\
\% \text { unwashed }\end{array}$ & $\begin{array}{c}\text { Total CFE as \% } \\
\text { unwashed }\end{array}$ \\
\hline \multirow[t]{3}{*}{1} & $5 \mathrm{~min}$ & 1.50 & 0.17 & 1.67 & 28.3 & 37.7 \\
\hline & $20 \mathrm{~min}$ & 2.80 & 0.30 & 3.10 & 50.0 & 70.0 \\
\hline & Unwashed & 3.83 & 0.60 & 4.43 & 100.0 & 100.0 \\
\hline \multirow[t]{3}{*}{2} & $5 \mathrm{~min}$ & 0.16 & 0.07 & 0.23 & 28.0 & 46.0 \\
\hline & $20 \min$ & 0.20 & 0.20 & 0.40 & 80.0 & 80.0 \\
\hline & Unwashed & 0.25 & 0.25 & 0.50 & 100.0 & 100.0 \\
\hline \multirow[t]{3}{*}{3} & $5 \mathrm{~min}$ & 1.27 & 0.03 & 1.30 & 17.6 & 58.5 \\
\hline & $20 \min$ & 1.16 & 0.15 & 1.32 & 88.0 & 59.5 \\
\hline & Unwashed & 2.05 & 0.17 & 2.22 & 100.0 & 100.0 \\
\hline \multirow[t]{3}{*}{4} & $5 \mathrm{~min}$ & 0.23 & 0.09 & 0.32 & 45.0 & 41.0 \\
\hline & $20 \mathrm{~min}$ & 0.33 & 0.11 & 0.44 & 55.0 & 56.4 \\
\hline & Unwashed & 0.57 & 0.20 & 0.78 & 100.0 & 100.0 \\
\hline \multirow[t]{3}{*}{5} & $5 \mathrm{~min}$ & 7.00 & 0.60 & 7.60 & 58.3 & 42.2 \\
\hline & $20 \min$ & 10.63 & 0.77 & 11.40 & 74.8 & 63.3 \\
\hline & Unwashed & 16.97 & 1.03 & 18.0 & 100.0 & 100.0 \\
\hline \multirow[t]{3}{*}{ Mean } & $5 \mathrm{~min}$ & 2.03 & 0.19 & 2.22 & 35.4 & 45.1 \\
\hline & $20 \min$ & 3.02 & 0.31 & 3.33 & 69.6 & 65.8 \\
\hline & Unwashed & 4.73 & 0.45 & 5.19 & 100.0 & 100.0 \\
\hline
\end{tabular}

${ }^{a}$ Data from five experiments showing the numbers of colonies produced by $10^{3}$ cells allowed to attach to collagen-coated dishes for 5 or 20 minutes before washing off unattached cells, or from unwashed dishes. Colonies were allowed to grow for 14 days before fixing and staining for colony scoring as before.

CFE, colony-forming efficiency.

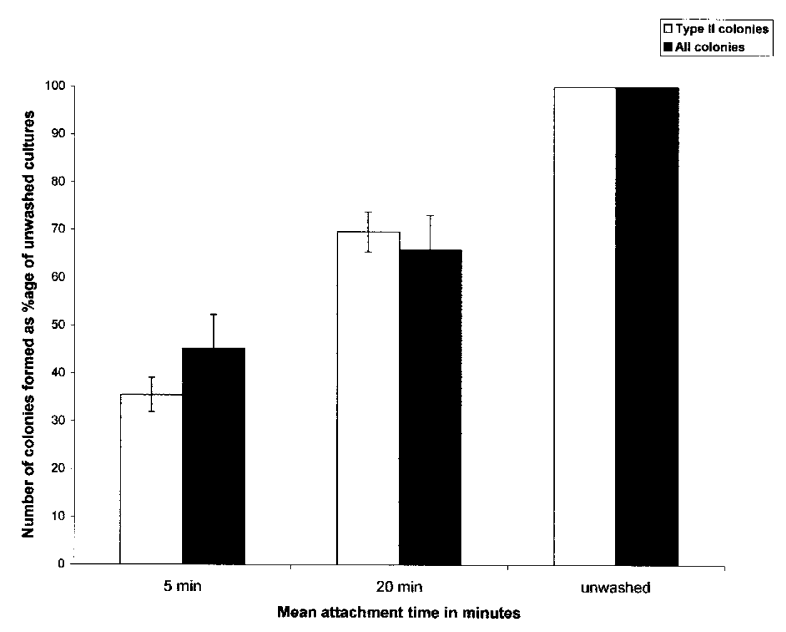

Figure 4.

Graph showing time course of attachment of freshly isolated epithelial cells to collagen I. Mean colony numbers formed after attachment of cells to collagen I for 5 or 20 minutes is expressed as a percentage of attachment of unselected cells. Error bars represent the SEM of 5 experiments.

supplemented with 20 mmol HEPES (Sigma Chemical Company, Poole, United Kingdom), 5\% fetal calf serum (Sigma), penicillin (10 U/ml) and streptomycin (10 $\mu \mathrm{g} / \mathrm{ml}$ ), fungizone (Amphotericin B, $2.5 \mu \mathrm{g} / \mathrm{ml}$ ), and 2 mmol L-glutamine (all from Life Technologies). The samples were confirmed by histopathology to be benign prostatic hyperplasia and to be free of malignancy.

\section{Primary Cell Culture}

Cells were isolated from freshly collected prostate tissue using a method modified from that previously described (Fry et al, 2000). Briefly, tissue was cut into $1 \mathrm{~mm}$ cubes and digested for 18 hours at $37^{\circ} \mathrm{C}$ in 200 $\mathrm{IU} / \mathrm{ml}$ collagenase type IA (Sigma). The collagenasedigested tissue was washed twice in PBS before sedimentation of the epithelial acini by centrifugation at $57 \times g$ for 20 seconds. A single cell suspension was produced from the acini by digestion of the pellet for 45 minutes at $37^{\circ} \mathrm{C}$ in $0.25 \%$ trypsin/versene in buffered saline. Cells were plated at 1000 cells per $6-\mathrm{cm}$ dish in the presence of a feeder layer of lethally irradiated NIH 3T3 cells. The feeder cells were used to help maintain clonal growth of the cells. Petri dishes were precoated with $10 \mu \mathrm{g} / \mathrm{ml}$ collagen type I (Vitrogen 100; Imperial Laboratories, Andover, United Kingdom) in PBS for 1 hour at $37^{\circ} \mathrm{C}$. Cells were grown in serum-free prostate epithelial growth medium (PrEGM; Clonetics, BioWhittaker UK Ltd., Wokingham, United Kingdom) as done previously (Fry et al, 2000). Cultures were grown for 14 days and fixed in ice-cold 1:1 methanol:acetone for immunochemistry or in $4 \%$ neutral buffered formalin (Merck, Poole, United Kingdom) for colony scoring. Dishes for colony scoring were stained for 30 minutes with 1\% Rhodanile (Rheinwald and Green, 1975).

For three-dimensional culture, individual colonies were ring-cloned and harvested using trypsin/versene. After neutralizing the trypsin with DMEM (Life Technologies) containing $10 \%$ FCS, harvested cells were centrifuged and washed in PrEGM, and cells from single colonies were plated separately into individual wells containing $200 \mu$ l of Matrigel (Stratech Scientific, Luton, United Kingdom). The wells containing Matrigel were overlaid with PrEGM in the presence of mibolerone (NEN Life Sciences, Hounslow, United Kingdom) at $10^{-9} \mathrm{M}$ and $50 \%$ stromal cell-conditioned 

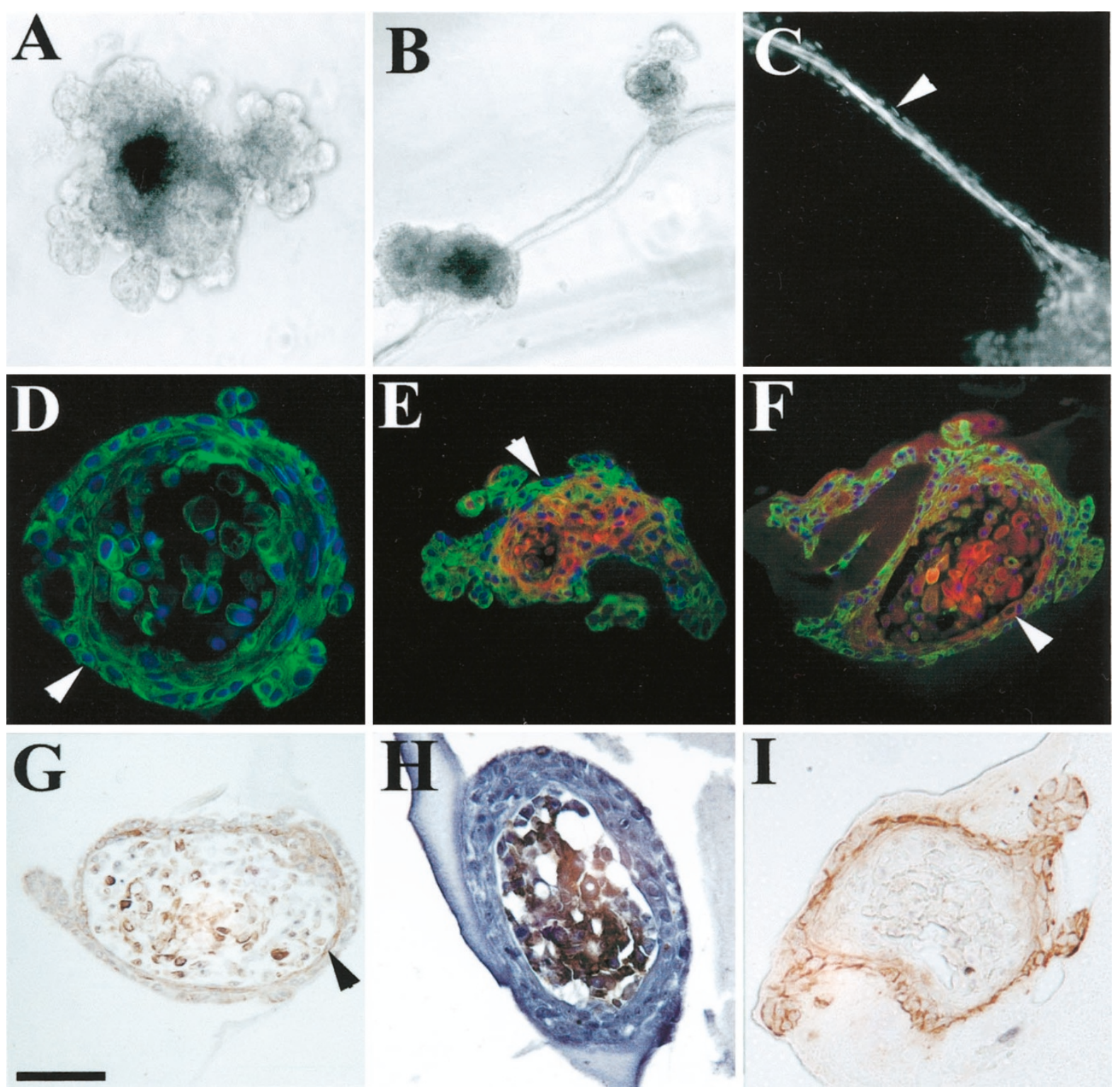

\section{Figure 5.}

Analysis of three-dimensional epithelial cell cultures. Type II colonies were ring cloned and transferred to individual wells of a 24-well plate containing Matrigel. Cells were grown for 17 days in the presence of stromal cell-conditioned medium and $10^{-9} \mathrm{M}$ Mibolerone, fixed, paraffin-embedded, and cut into $5 \mu \mathrm{m}$ sections. A and B, Phase contrast images of structures produced in Matrigel after 17 days in culture. C, Hoechst staining showing detail of connecting duct. D to I, Sections of cultured cells stained for D, K5; E, K14 (green) and K17 (red); F, K14 (green) and K19 (red); G, K8; H, androgen receptor; and I, CD44. Immunofluorescent detection by FITC-conjugated anti-rabbit (D), or Ig-isotype specific conjugates (E, F). Antibodies in G to I were detected with diaminobenzidine using the ABC-Elite Kit (Vector). Note preferential staining of a basal layer with anti-K5 (arrow in D) and anti-K14 (arrow in E), inner layer staining with anti-K19 (F), and the formation of an inner lumen. Bar in G represents approximately $175 \mu \mathrm{m}$ in A, $450 \mu \mathrm{m}$ in B and C, and $75 \mu \mathrm{m}$ in D to I.

PrEGM. Stromal cell-conditioned PrEGM was prepared by growing prostate stromal cells in DMEM with $10 \%$ FCS to subconfluence and then incubating the cells for a further 48 hours in PrEGM. The harvested conditioned medium was sterilized using a $0.22 \mu$ filter and stored for up to 14 days at $4^{\circ} \mathrm{C}$. Using a microscope-mounted Olympus $35 \mathrm{~mm}$ camera, the cultures were photographed every 3 days for 17 days, at which point the cultures were fixed in $4 \%$ formalin for 15 minutes and processed for paraffin embedding. These are growth conditions similar to those used by Webber et al (1997) to show acinar morphogenesis of immortalized epithelial cells grown on Matrigel.

\section{Clonogenicity}

The colony-forming efficiency of primary prostate epithelial cells was determined by counting colonies containing more than 32 cells after 14 days of culture, as a percentage of the total number of cells plated (1000) in triplicate sets of $6-\mathrm{cm}$ dishes. The number of cells within each colony was determined either by direct counting, in the case of the smaller colonies, or by determining the mean cell number per linear millimeter and estimating the number of cells per square millimeter. Using a $1 \mathrm{~mm}$ grid on acetate circles, the area of individual colonies was estimated and the total number of cells calculated. 
Table 3. Antibody Reagents

\begin{tabular}{lllllll}
\hline Antigen & Clone & Species & Isotype & Dilution & \multicolumn{1}{c}{ Source } & \multicolumn{1}{c}{ Reference } \\
\hline K5 & BL18 & Rabbit & Polyclonal & $1: 200$ & Gift, EB Lane & na \\
K8 & 35 $\beta$ H11 & Mouse & $\operatorname{IgM}$ & $1: 40$ & Dako & Gown and Vogel, 1984 \\
K14 & LL002 & Mouse & $\operatorname{IgG3}$ & $1: 10$ & Gift, EB Lane & Purkis et al, 1990 \\
K17 & E3 & Mouse & $\operatorname{IgG2b}$ & $1: 100$ & Sigma & Guelstein et al, 1988 \\
K19 & LP2K & Mouse & $\operatorname{IgG2b}$ & $1: 10$ & Gift, EB Lane & Stasiak et al, 1989 \\
AR & F39.4.1 & Mouse & IgG1 & $1: 100$ & Biogenex & Ruizeveld de Winter et al, 1991 \\
CD44 & E 1/2.8 & Mouse & IgG1 & $1: 100$ & Gift, C. Isacke & Isacke et al, 1986 \\
\hline
\end{tabular}

\section{Differential Adhesion}

The attachment of colony-forming epithelial cells to extracellular collagen I was assessed by allowing 1000 cells to settle onto collagen I-coated dishes. Unattached cells were removed by gentle rinsing with PBS, and then lethally irradiated NIH-3T3 cells were added to the dishes, which were then cultured for 14 days. Colony formation was scored as described above. Dishes were coated by incubation for 1 hour at $37^{\circ} \mathrm{C}$ with $3 \mathrm{ml}$ of a solution of Vitrogen 100 in PBS and then washed twice in PBS before use. An optimal coating concentration of $10 \mu \mathrm{g} / \mathrm{ml}$ was established by coating dishes with 1 to $50 \mu \mathrm{g} / \mathrm{ml}$ of collagen I and determining the concentration at which the maximum number of cells attached in 5 minutes. To examine the accumulation of attached cells with time, cells were allowed to settle onto coated dishes for 5 or 20 minutes before washing. In control dishes the unattached cells were not removed by washing.

\section{Antibodies and Immunochemistry}

The primary antibodies used are listed in Table 3. Background staining was blocked with L15 medium (Life Technologies) containing 10\% FCS (vol/vol) for 1 hour at room temperature before incubation for 1 hour with primary antibodies, diluted in blocking solution. After washing three times in PBS, dishes were incubated for 45 minutes with Ig subtype-specific antimouse antibodies conjugated to fluorescein isothiocyanate or tetramethyl rhodamine isothiocyanate (Southern Biotechnology Association, Inc., Birmingham, Alabama). For rabbit primary antibodies, fluorescein isothiocyanate-conjugated anti-rabbit secondary antibody was used (Dako, Cambridge, United Kingdom). Cell nuclei were stained with a $1 \mu \mathrm{g} / \mathrm{ml}$ solution of Hoechst 33258 (Sigma) for 5 minutes.

For staining of paraffin-embedded sections, antibodies recognizing $\mathrm{CD} 44, \mathrm{~K} 8$, and the androgen receptor were detected with an immunoperoxidase method using a standard avidin-biotin-complex kit (Vector Elite; Vector Laboratories, Peterborough, United Kingdom). Antibody binding was visualized using 3,3'-diaminobenzidine (DAB, Vector Laboratories). Sections were counterstained with Mayers hematoxylin, dehydrated and mounted in DPX (Merck).

Paraffin-embedded sections required antigen retrieval by microwaving in a citrate-based buffer (antigen unmasking solution, Vector Laboratories) for 30 minutes. Sections were incubated overnight with primary antibodies before proceeding as described above.

\section{Image Capture and Microscopy}

Sections were examined under a Hg-arc Zeiss axiophot fluorescence microscope fitted with a band-pass filter for optimal FITC/TRITC separation. This was coupled to a coolview 12 cooled charge-coupledevice camera $(1024 \times 1024,12$ bit pixels) (Photonic Science, Robertsbridge, United Kingdom) controlled by Image Pro-Plus 3.0 (Media Cybernetics, Silver Spring, Maryland). The image obtained with each antigen was stored separately as a data-file. To generate coincident two-color images, files were merged and given computer-generated colors using Adobe Photoshop 5.0 (Adobe Systems, Inc., San Jose, California). Images from sections processed using DAB detection were captured using a Leaf MicroLumina high-resolution scanning camera $(2280 \times 2699$ pixels, total output per image data file) (Leaf Systems, Inc., ISS, Greater Manchester, United Kingdom) and processed as above.

\section{Acknowledgements}

The authors thank all those who contributed tissue for this study and those who provided antibodies, especially Professor Birgitte Lane for the keratin reagents. Thanks to Sai-mann Ma for excellent technical assistance.

\section{References}

Akiyama M, Smith LT, and Shimizu H (2000). Changing patterns of localization of putative stem cells in developing human hair follicles. J Invest Dermatol 114:321-327.

Barrandon Y and Green H (1987). Three clonal types of keratinocyte with different capacities for multiplication. Proc Natl Acad Sci USA 84:2302-2306.

Bayne CW, Ross M, Donnelly F, Chapman K, Buck C, Bollina P, and Habib FK (1998). Selective interactions between prostate fibroblast and epithelial cells in co-culture maintain the BPH phenotype. Urol Int 61:1-7.

Bonkhoff $\mathrm{H}$ and Remberger K (1996). Differentiation pathways and histogenetic aspects of normal and abnormal prostatic growth: A stem cell model. Prostate 28:98-106. 
Bonkhoff H, Stein U, and Remberger K (1994). The proliferative function of basal cells in the normal and hyperplastic human prostate. Prostate 24:114-118.

De Marzo AM, Meeker AK, Epstein Jl, and Coffey DS (1998). Prostate stem cell compartments. Expression of the cell cycle inhibitor p2 $7^{\mathrm{kip} 1}$ in normal, hyperplastic, and neoplastic cells. Am J Pathol 153:911-919.

Fry PM, Hudson DL, O'Hare MJ, and Masters JRW (2000). Comparison of marker protein expression in benign prostatic hyperplasia in vivo and in vitro. BJU Int 85:504-513.

Gown AM and Vogel AM (1984). Monoclonal antibodies to human intermediate filament proteins. II. Distribution of filament proteins in normal human tissues. Am $\mathrm{J}$ Pathol 114: 309-321.

Guelstein VI, Tchypysheva TA, Ermilova VD, Litvinova LV, Troyanovsky SM, and Bannikov GA (1988). Monoclonal antibody mapping of keratins 8 and 17 and of vimentin in normal human mammary gland, benign tumors, dysplasias, and breast cancer. Int J Cancer 42:147-153.

Isaacs JT and Coffey DS (1989). Etiology and disease process of benign prostatic hyperplasia. Prostate Suppl 2:3350 .

Isacke CM, Sauvage CA, Hyman R, Lesley J, Schulte R, and Trowbridge IS (1986). Identification and characterisation of the human Pgp-1 glycoprotein. Immunogenetics 23:326332.

Jones PH, Harper S, and Watt FM (1995). Stem cell patterning and fate in human epidermis. Cell 80:83-93.

Jones PH and Watt FM (1993). Separation of human epidermal stem cells from transit amplifying cells on the basis of differences in integrin function and expression. Cell 73:713724.

Landis SH, Murray T, Bolden S, and Wingo PA (1999). Cancer statistics. CA Cancer J Clin 9:8-31.

Li A, Simmons PJ, and Kaur P (1998). Identification and isolation of candidate human keratinocyte stem cells based on cell surface phenotype. Proc Natl Acad Sci USA 95:39023907.

Liu AY, True LD, LaTray L, Nelson PS, Ellis WJ, Vessella RL, Lange PH, Hood L, and van den Engh G (1997). Cell-cell interaction in prostate gene regulation and cytodifferentiation. Proc Natl Acad Sci USA 94:10705-10710.

Molès J-P and Watt FM (1997). The epidermal stem cell compartment: Variation in expression levels of E-cadherin and catenins within the basal layer of human epidermis. J Histochem Cytochem 45:867-874.

Oesterling JE (1995). Benign prostatic hyperplasia. Medical and minimally invasive treatment options. $\mathrm{N}$ Engl $\mathrm{J}$ Med 332:99-109.

Peehl DM and Stamey TA (1986). Serum-free growth of adult human prostatic epithelial cells. In Vitro Cell Dev Biol 22:8290.
Peehl DM, Wong ST, and Stamey TA (1988). Clonal growth characteristics of adult human prostatic epithelial cells. In Vitro Cell Dev Biol 24:530-536.

Potten CS and Loeffler M (1990). Stem cells: Attributes, cycles, spirals, pitfalls, and uncertainties. Lessons for and from the crypt. Development 110:1001-1020.

Purkis PE, Steel JB, Mackenzie IC, Nathrath WB, Leigh IM, and Lane EB (1990). Antibody markers of basal cells in complex epithelia. J Cell Sci 97:39-50.

Reiter RE, Gu Z, Watabe T, Thomas G, Szigeti K, Davis E, Wahl M, Nisitani S, Yamashiro J, Le Beau M, Loder M, and Witte ON (1998). Prostate stem cell antigen: A cell surface marker overexpressed in prostate cancer. Proc Natl Acad Sci USA 95:1735-1740.

Rheinwald JG and Green H (1975). Serial cultivation of strains of human epidermal keratinocytes: The formation of keratinizing colonies from single cells. Cell 6:331-343.

Robinson EJ, Neal DE, and Collins AT (1998). Basal cells are progenitors of luminal cells in primary cultures of differentiating human prostatic epithelium. Prostate 37:149-160.

Ruizeveld de Winter JA, Trapman J, Vermey M, Mulder E, Zegers ND, and van der Kwast TH (1991). Androgen receptor expression in human tissues: An immunohistochemical study. J Histochem Cytochem 39:927-936.

Stasiak PC, Purkis PE, Leigh IM, and Lane EB (1989). Keratin 19: Predicted amino acid sequence and broad tissue distribution suggest it evolved from keratinocyte keratins. J Invest Dermatol 92:707-716.

Watt FM (1989). Terminal differentiation of epidermal keratinocytes. Curr Opin Cell Biol 1:1107-1115.

Webber MM, Bello D, Kleinman HK, and Hoffman MP (1997). Acinar differentiation by non-malignant immortalized human prostatic epithelial cells and its loss by malignant cells. Carcinogenesis 18:1225-1231.

Xue Y, Smedts F, Umbas R, Aalders TW, Debruyne FM, de la Rosette JJ, and Schalken JA (1997). Changes in keratin expression during the development of benign prostatic hyperplasia. Eur Urol 32:332-338.

Xue Y, Smedts F, Verhofstad A, Debruyne F, de la Rosette J, and Schalken J (1998). Cell kinetics of prostate exocrine and neuroendocrine epithelium and their differential interrelationship: New perspectives (review). Prostate Suppl 8:62-73.

Zhu AJ and Watt FM (1999). $\beta$-catenin signalling modulates proliferative potential of human epidermal keratinocytes independently of intercellular adhesion. Development 126: 2285-2298. 